Document downloaded from:

http://hdl.handle.net/10251/123471

This paper must be cited as:

Navarro Esteve, PJ.; Yudici Oliver, SA.; Herráez Boquera, J.; Denia Rios, JL.; Martín Sánchez, MT.; Rodríguez Pereña, J. (2018). Restoration of paintings on domes with nondevelopable geometry (Los Santos Juanes Church in Valencia). International Journal of Architectural Heritage. 12(2):169-177. https://doi.org/10.1080/15583058.2017.1356946

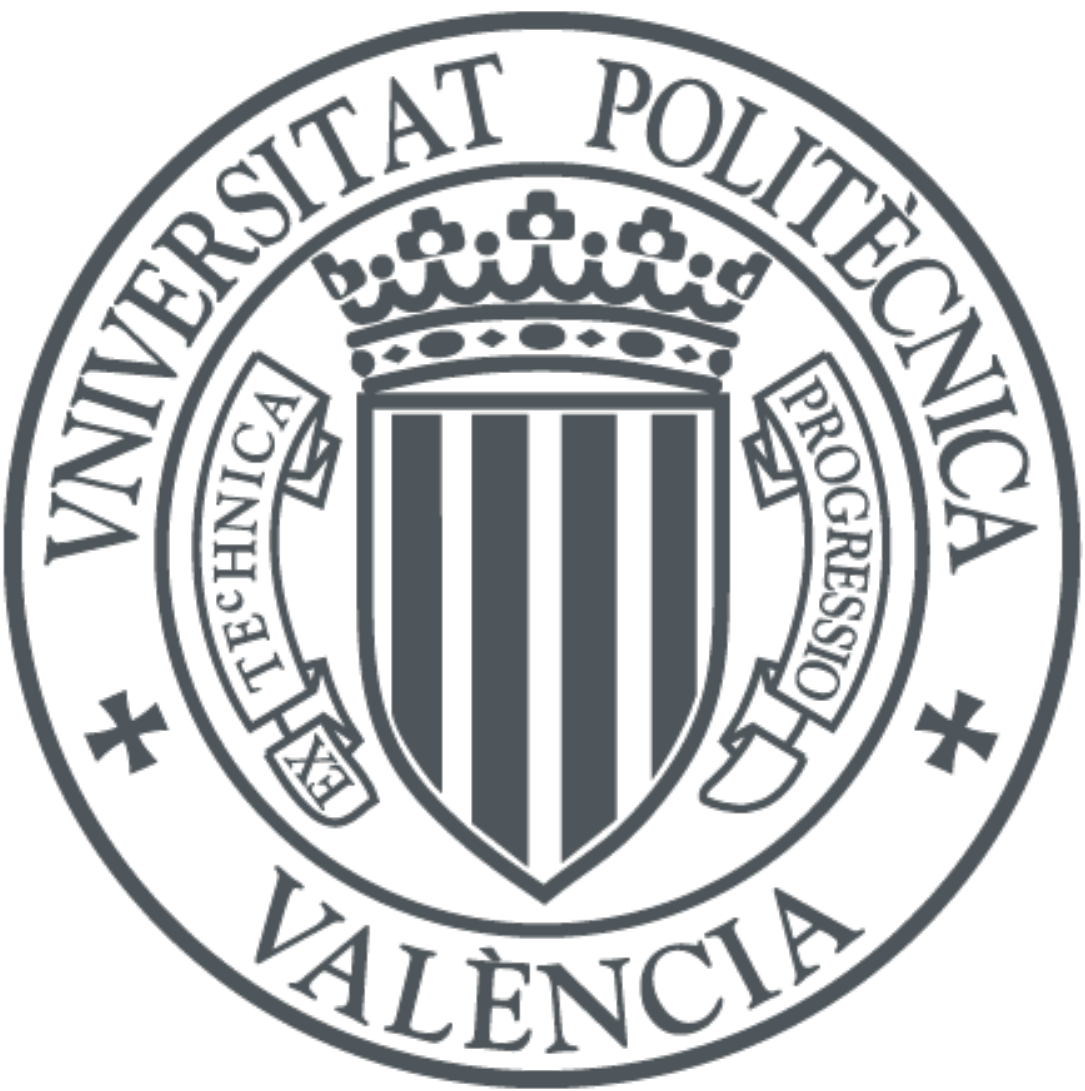

The final publication is available at

http://doi.org/10.1080/15583058.2017.1356946

Copyright Taylor \& Francis

Additional Information 


\title{
DEVELOPMENT OF IRREGULAR GEOMETRY DOMES FOR PAINTING RESTORATION (LOS SANTOS JUANES CHURCH IN VALENCIA) RESTORATION OF PAINTINGS ON DOMES WITH NON-DEVELOPABLE GEOMETRY (LOS SANTOS JUANES CHURCH IN VALENCIA)
}

\author{
Navarro, P. ${ }^{\text {a }}$, Yudici, S. ${ }^{\mathrm{a}}$, Herráez, J. ${ }^{\mathrm{b}}$, Denia, J.L. ${ }^{\mathrm{b}}$, Martin, M.T. ${ }^{\mathrm{c}}$ and Rodriguez, J.. ${ }^{\text {** }}$ \\ ${ }^{a}$ School of Architecture (Polytechnic University of Valencia). 46022, Valencia (Spain). \\ ${ }^{\mathrm{b}}$ School of Civil Engineering (Polytechnic University of Valencia). 46022, Valencia (Spain). \\ ${ }^{c}$ Polytechnic College at Lugo (University of Santiago de Compostela). 27002, Lugo (Spain). \\ *corresponding author: jaime.rodriguez@usc.es
}

\begin{abstract}
The restoration of paintings on elements in cultural heritage buildings (fundamentally, churches) involves two structural problems: capturing the geometry of the construction element and its development. In many cases, the geometries are regular (e.g., cylinders, spheres, elliptical domes). However, there are cases in which the elements cannot be adapted to any known geometry, much less one that can be mathematically developed. The development of surfaces becomes essential for the restoration of paintings over "flat elements" (over which work is performed on the ground) that are subsequently transferred to the real surface (ceilings). The mathematical transformations that allow regular geometries to be developed are widely known (cartographic projections). However, when the geometry is irregular, there is no development. This study presents a new methodology based on differential rectification and its application for the development of oculi in the Los Santos Juanes Church (Valencia), whose geometry is completely irregular both in shape and as a result of construction defects (and damage caused by fire). The present study focuses on the restoration of paintings damaged by fire.
\end{abstract}

Keywords: 3D model, measurement, simplification, laser scanner 


\section{Introduction}

For cultural heritage to endure for a long period of time and be preserved for future generations, it is vital to exhaustively analyse its current state. Churches are one of the most significant types of constructions from the perspective of heritage value. Within this field, numerous conservation studies have been conducted in recent decades and continue to be studied due to their enormous importance (Baraccani, S. et al., 2016; Sanchez, A. et al., 2016; Coronelli, D et al., 2015). As a result of the evolution of equipment related to different fields in the study of conservation and restoration, restoration jobs that were complex and laborious only a few years ago can now be performed precisely and quickly. There is also the additional advantage that many of these new technologies enable heritage sites to be analysed in a noninvasive manner.

In the specific case of the restoration and conservation of paintings (frescoes), churches hold artwork of incalculable value, and their conservation has been a subject of study for several decades (or even centuries). Among these studies, work has focused on the state of paintings (e.g., colours, properties) and their restoration (Sfarra, S., 2015; Rosado, T., 2014; Bianchin, S. et al., 2009). These studies require complementary studies that examine the exact geometry of the surface over which they were created. As a result, it is now common to perform measuring, 3D modelling, and mapping using laser scanner and photogrammetry techniques (Lezzerini, M. et al., 2016; Guarnieri, A. et al., 2013, [14, 15]). Over the past decade, these tools and techniques have been in mass use. In addition, there are interesting visualization options that may be of great help (Munoz, F. et al., 2014; Galiana, M., 2014).

Geometry is a determining element given that its alteration affects aesthetic properties whose value cannot be challenged in addition to running the risk of seeming to affect the structure in terms of its dimensional and/or structural stability. Laser scanning is the optimal information-capturing instrument [59] because it is capable of providing millions of points in seconds, generating a three-dimensional model with high precision [1-4].

However, the use of lasers represents a problem. Although the ability to capture the greatest amount of geometrical information possible is its greatest virtue, excessive information of this type is a problem in terms of data processing [16]. The geometry on which restored paintings were created must be defined with the greatest possible precision and the minimum number of points. In other words, to develop in $2 \mathrm{D}$ the surface to be restored through a projection, it is necessary to model this surface with a number of points that allows for its development. 
Therefore, it is first necessary to simplify the point cloud provided by the laser without altering its geometry (Measurement 3). Subsequently, it is necessary to develop the surface through a projection that conserves its properties. From this perspective, the known algorithms (based on cartographical projections) are only applicable to regular surfaces (e.g., spheres, cylinders) but are of no use when the surface is irregular.

This study presents the development of several ceiling elements in the Los Santos Juanes Church in Valencia through a new methodology based on differential rectification. To confirm that this methodology works, it is applied to two surfaces that can be developed through conventional means to verify its worth. Subsequently, the methodology is applied to oculi from the church that were destroyed by fire and whose geometry is completely irregular. Finally, the paintings are developed for restoration following the methodology.

\section{Development of irregular surfaces (non-developable) in 2D}

To develop a surface, the angles, the distances, or the areas must be conserved, but conserving all of them simultaneously is impossible. Constant scale projections conserve distances, authalic projections conserve areas, autogonal projections reduce angular deformations to a minimum, aphylactic projections reduce linear deformations to a minimum, and perihallic projections produce minimal surface deformations. Because it is not possible to perform constant scale development in an irregular element, the solution must consist of a combination of an aphylactic projection and a conformal projection.

For the development algorithm to conserve the distances between three-dimensional points, $D_{i j}$, the distance projected $d_{i j}$ between those two points in the development is given as follows:

$$
d_{i j}=\sqrt{\left(x_{j}-x_{i}\right)^{2}+\left(y_{j}-y_{i}\right)^{2}}+r_{i j}
$$

where

$r_{i j}$ : the remainder of the distance in the development;

$\left(x_{i}, y_{i}, 0\right)$ : the coordinates of a point in space $(X, Y, Z)$ on the projected plane; and

$D_{i j}=\sqrt{\left(X_{j}-X_{i}\right)^{2}+\left(Y_{j}-Y_{i}\right)^{2}+\left(Z_{j}-Z_{i}\right)^{2}}:$ the real distance between two points in space.

Similarly, for the algorithm to conserve the angle between two vectors in space $\Omega$ (defined by three points: $\mathrm{i}, \mathrm{j}$, and $\mathrm{k}$ ), the projected angle $w$ is given by its scalar product as follows:

$$
\omega=\operatorname{Arccos} \frac{\left(\left(x_{j}-x_{i}\right) *\left(x_{k}-x_{i}\right)+\left(y_{j}-y_{i}\right) *\left(y_{k}-y_{i}\right)+\left(z_{j}-z_{i}\right) *\left(z_{k}-z_{i}\right)\right)}{\sqrt{\left(x_{j}-x_{i}\right)^{2}+\left(y_{j}-y_{i}\right)^{2}+\left(z_{j}-z_{i}\right)^{2}}+\sqrt{\left(x_{k}-x_{i}\right)^{2}+\left(y_{k}-y_{i}\right)^{2}+\left(z_{k}-z_{i}\right)^{2}}}+r_{i},
$$

where

$r_{i}$ : the remainder of the development angle; and 


$$
\Omega=\operatorname{Arccos} \frac{\left(\left(X_{j}-X_{i}\right) *\left(X_{k}-X_{i}\right)+\left(Y_{j}-Y_{i}\right) *\left(Y_{k}-Y_{i}\right)+\left(Z_{j}-Z_{i}\right) *\left(Z_{k}-Z_{i}\right)\right)}{\sqrt{\left(X_{j}-X_{i}\right)^{2}+\left(Y_{j}-Y_{i}\right)^{2}+\left(Z_{j}-Z_{i}\right)^{2}}+\sqrt{\left(X_{k}-X_{i}\right)^{2}+\left(Y_{k}-Y_{i}\right)^{2}+\left(Z_{k}-Z_{i}\right)^{2}}}: \text { the }
$$

angle formed by two vectors in space.

Precision in the surface development, based on both conditions described above, depends on the number of points on the surface that provide the most exact knowledge of its geometry. Because we have a dense cloud resulting from the laser scan, we adjust a Delaunay triangulation, obtaining a continuous surface of triangles that adjusts to the real surface with great precision (with an error of one-tenth of the length of the sides used in the triangulation).

The result of developing this triangulated surface is another triangulated surface with the same number of points, sides, and triangles. If the real surface were developable, then the developed surface would be formed by triangles of the same dimension as the original. Because it is not, the developed triangles can conserve the angles, distances, surfaces, or some combination of these based on the conditions that we impose on the adjustment of the network. The solution consists of a system of equations of conservation of angles and/or distances, minimizing the remainders between the real measurements and the projected measurements through a least quadratic adjustment.

The conservation of angles is not possible except in cases in which the adjacent triangles surrounding a point add up to $400 \mathrm{~g}$ (for which all points must be in the same plane in space, in which case the real surface and the developed surface would be the same). In any other case, the sum of the angles of the triangles that converge on a point in space will not be $400 \mathrm{~g}$, and their homologous values in the development must add up to that number. To solve this problem, it is possible to generate a tangent plane on each point or the direction of a normal line, projecting the real angles on it through the vectorial product of the sides that converge in one point:

$$
V_{P_{i j}}=\frac{L_{i} * L_{j}}{\left|L_{i} * L_{j}\right|},
$$

where

$L_{i}, L_{j}:$ two vectors that start at the vertex and have the direction and orientation of the two sides that compose the angle on which a perpendicular line is obtained; and $V_{P_{i}}:$ the resulting unitary vector perpendicular to the triangle.

Finally, accepting as the normal surface in one point the average of lines normal to the triangles that coincide on it,

$$
V_{P}=\frac{1}{n} \sum_{1}^{n} V_{P_{i j}},
$$

where

$V_{P}$ : the average vector of the $\mathrm{n}$ vectors that are perpendicular to the triangles given their common vertex.

For each side of the triangle, we calculate a vector that is perpendicular to it and to the normal line previously obtained: 


$$
V_{P P_{i}}=\frac{V_{P} * L_{i}}{\left|V_{P} * L_{i}\right|} \quad V_{P P_{j}}=\frac{V_{P} * L_{j}}{\left|V_{P} * L_{j}\right|},
$$

where

$$
V_{P P_{i}}, V_{P P_{j}} \text { : unitary vectors that are perpendicular to } V_{P} \text { and to } L_{i} \text { or } L_{j} \text {. }
$$

The angle between two sides of the triangle projected on the tangent plane is the same as that obtained through its perpendicular directions (5), which is why the angle is given by the cosine theorem. Through this procedure, the sum of the angles of the triangles contiguous on a vertex inside the surface add up to $400 \mathrm{~g}$, whereas the sum of the interior angles of the triangles do not add up to $200 \mathrm{~g}$.

The formulated system results in a free network with three restrictions: two position restrictions $(\mathrm{X}, \mathrm{Y})$ and one rotation restriction. Given that the equations that form the adjustment system involve angle and distance, it is necessary to apply weighting as a function of the solution to address the conservation of one or the other. The formulation of the angle and distance equations makes it possible to obtain a system of equations with one equation for each side of each triangle as an angle equation and another equation for the distance in space that we wish to conserve. After linearization of the equations, we obtain a system of equations as follows:

$$
[A] *[x]=[K]+[R]
$$

where

$[A]$ : the matrix of coefficients for unknowns;

$[x]$ : the vector that contains the displacements that must be applied to the coordinates of the points for the system of equations to be optimal;

$[K]$ : the vector of independent terms in the equations; and

$[R]$ : the vector of the remainders of the angle and distance equations.

Depending on whether the intent is to conserve angles or distances, a different weighting must be performed as follows:

$$
[P] *[A] *[x]=[P] *[K]+[P] *[R],
$$

where $\mathrm{P}$ is the weight matrix.

The solution of the equation system that minimizes the sum of the squares of the results is the following:

$$
[x]=\left([A]^{t} *[P]^{t} *[P] *[A]\right)^{-1} *[A]^{t} *[P]^{t} *[P] *[K] .
$$

The remainder of each equation resulting from projecting the surface is the following:

$$
\begin{aligned}
& {[R]=[A] *[x]-[K]} \\
& {\left[R^{\prime}\right]=[P] *[A] *[x]-[P] *[K]}
\end{aligned}
$$

The value of sigma zero describes the mean tensile state of the surface and is obtained based on R' as follows:

where

$$
\sigma_{0}^{2}=\frac{\left[R^{\prime}\right]^{t} *\left[R^{\prime}\right]}{n_{0}-n_{i}}
$$


$n_{0}, n_{i}:$ the number of equations and the number of unknowns of the system.

\section{Results}

The Royal Parrish of Los Santos Juanes (Fig. 1a), designated a National Artistic Historic Monument, is gothic in origin but was re-built in the 14th and 16th centuries because of fires. Antonio Palomino painted the presbytery and all of the domes of the church in the last years of the 17th century, and in 1861, Luis López restored the paintings that were in poor shape. However, in 1936, due to damage and fires experienced during the Civil War, the paintings became black and sooty, and they are currently in the process of being restored. The section of the paintings that covers the dome of the presbytery has not been restored (Fig. 1b).
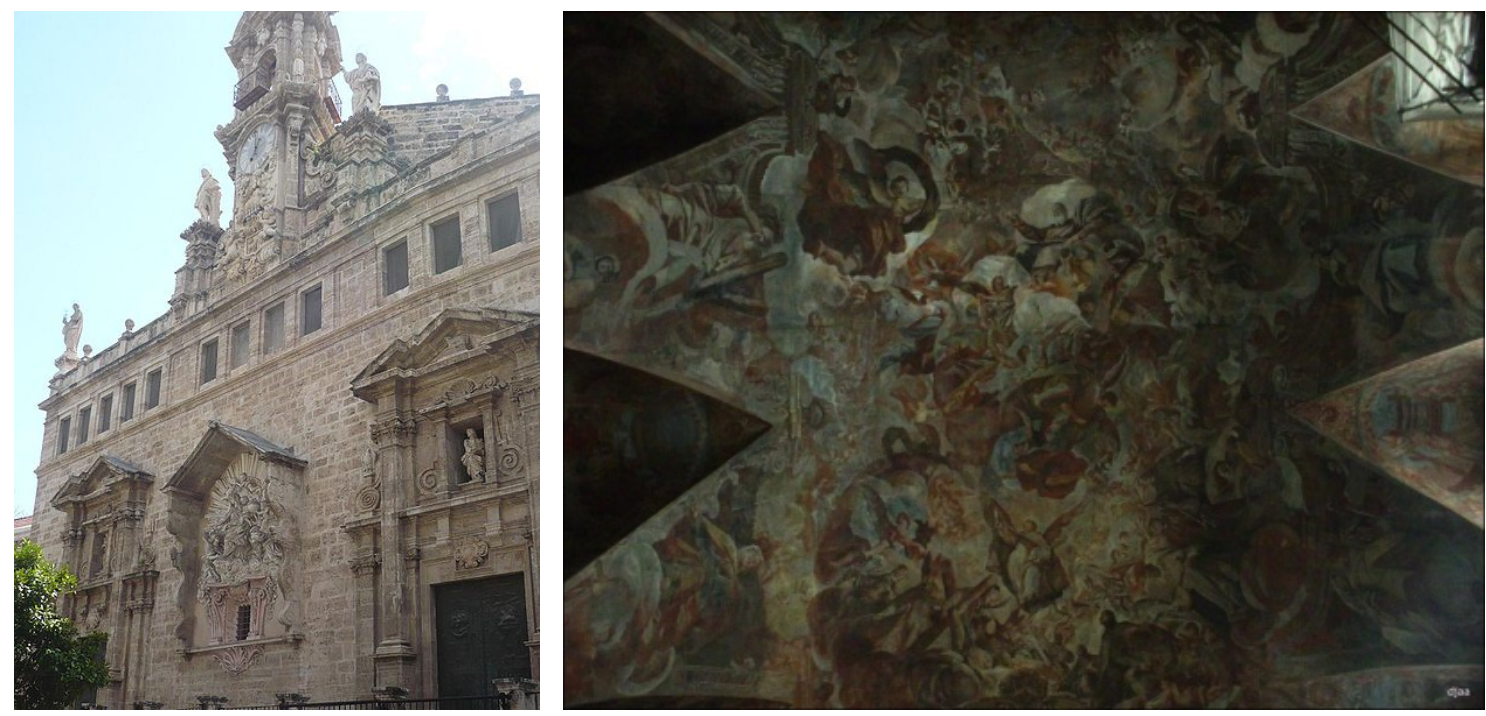

Figure 1: a) Façade of the Royal Parrish of Los Santos Juanes (Valencia). b) Partial view of the paintings on the dome that are being restored.

\subsection{Generating the 3D model}

The 3D geometry of the section studied here (Fig. 1b) was developed using a laser scanner (model Cyrax 2500). As shown in Figure 2, there is a cylindrical section (regular geometry with known mathematical development) and four occuli whose irregular geometry must be mathematically developed.
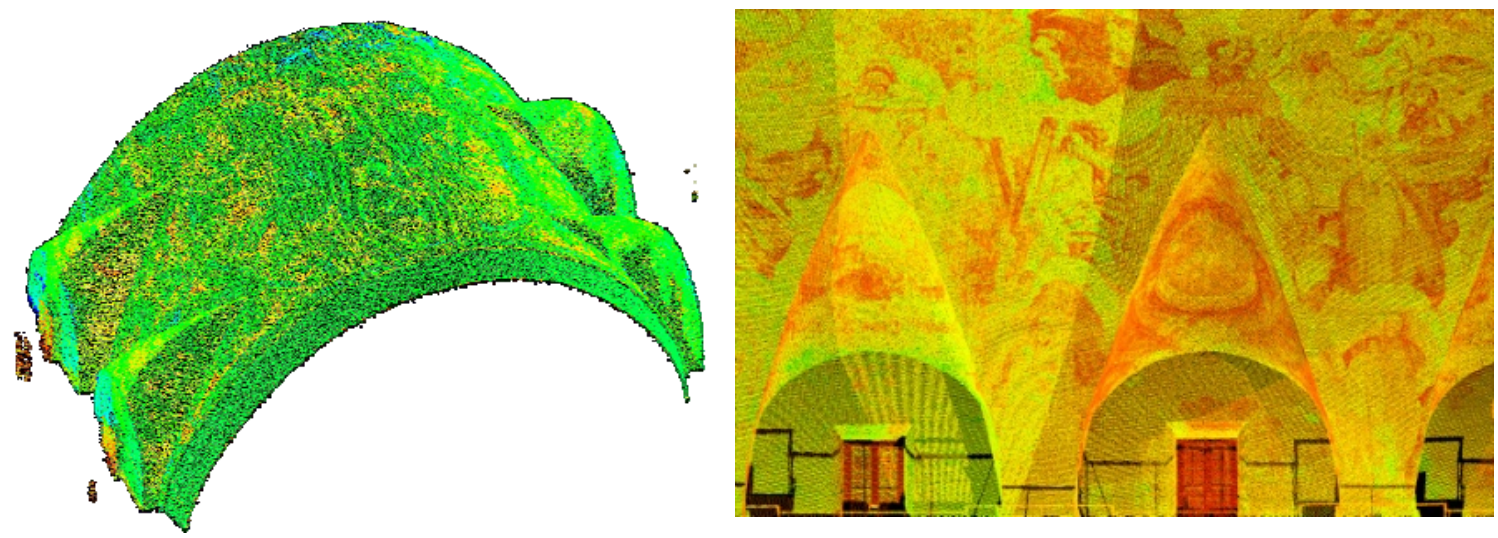
Figure 2: a) Three-dimensional model of the cylindrical dome with the four oculi, formed by 1,944,892 points (exterior view). b) Partial three-dimensional model with false colour image (interior view).

\subsection{Development of the cylindrical dome in 2D (regular surface)}

The result of the measurement in the restoration area shows that the cylindrical section has an approximate radius of $7.2 \mathrm{~m}$. The development of the cylindrical section is known based on the application of a projective linear transformation over a simplified point mesh (given the geometric regularity of the surface, calculating the transformation over all of the scanned points is unnecessary):

$$
\begin{aligned}
& \mathrm{x}_{\mathrm{f}}=\mathrm{x}+\mathrm{dx}=-\mathrm{f} \frac{\mathrm{m}_{11}\left(\mathrm{X}-\mathrm{X}_{0}\right)+\mathrm{m}_{12}\left(\mathrm{Y}-\mathrm{Y}_{0}\right)+\mathrm{m}_{13}\left(\mathrm{Z}-\mathrm{Z}_{0}\right)}{\mathrm{m}_{31}\left(\mathrm{X}-\mathrm{X}_{0}\right)+\mathrm{m}_{32}\left(\mathrm{Y}-\mathrm{Y}_{0}\right)+\mathrm{m}_{33}\left(\mathrm{Z}-\mathrm{Z}_{0}\right)} \\
& \mathrm{y}_{\mathrm{f}}=\mathrm{y}+\mathrm{dy}=-\mathrm{f} \frac{\mathrm{m}_{211}\left(\mathrm{X}-\mathrm{X}_{0}\right)+\mathrm{m}_{22}\left(\mathrm{Y}-\mathrm{Y}_{0}\right)+\mathrm{m}_{23}\left(\mathrm{Z}-\mathrm{Z}_{0}\right)}{\mathrm{m}_{31}\left(\mathrm{X}-\mathrm{X}_{0}\right)+\mathrm{m}_{32}\left(\mathrm{Y}-\mathrm{Y}_{0}\right)+\mathrm{m}_{33}\left(\mathrm{Z}-\mathrm{Z}_{0}\right)}
\end{aligned}
$$

where

$\left(\mathrm{x}_{\mathrm{f}}, \mathrm{y}_{\mathrm{f}}\right)$ : the coordinates of the points in the image (paintings);

$(\mathrm{X}, \mathrm{Y}, \mathrm{Z})$ : the coordinates of the points in the terrain (dome);

$(\mathrm{dx}, \mathrm{dy})$ : off-centre from the principal point of the image;

$\mathrm{f}$ : the focal distance of the camera; and

$\left(\mathrm{X}_{0}, \mathrm{Y}_{0}, \mathrm{Z}_{0}\right)$ : the coordinates in the terrain of the point of image capture (the optical centre of the camera).

The result of developing the cylindrical surface is found through generatrices, obtaining a set of rectangles that each cover 10 degrees over the generatrix (Fig. 3).
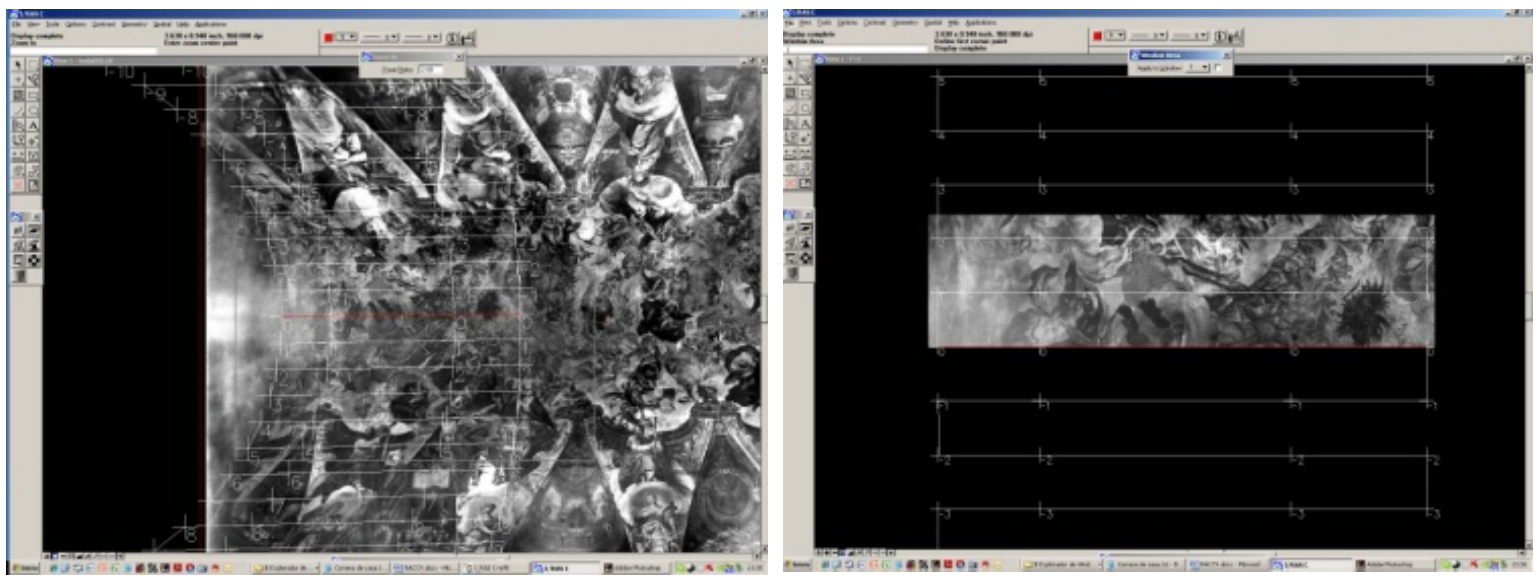

Figure 3: a) Calculation of generatrices over the image through projective transformation. b) Partial development of the image resulting from the rectification of a quadrilateral over the rectangle.

In this manner, using a mosaic of rectangles, we finally obtain the complete development (Fig. 4):

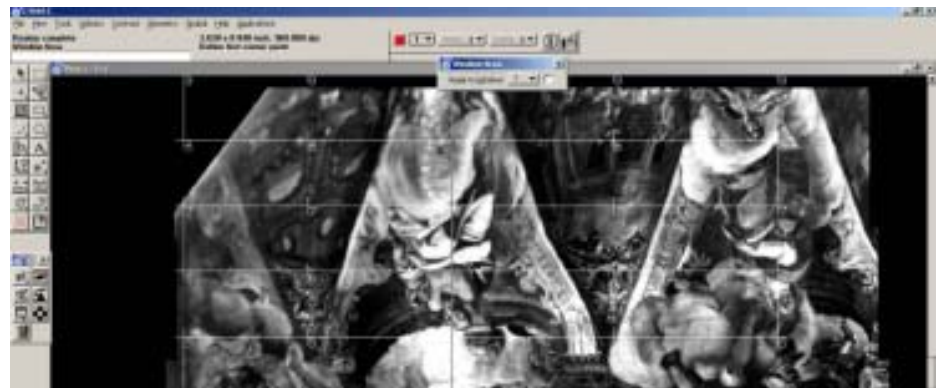


Figure 4: Mosaic of the 2D development.

\subsection{Development of one of the oculi in 2D (irregular surface)}

We select one of the oculi of the scanned cloud (Fig. 2b) by cutting away the three-dimensional work surface (Fig. 5a), which makes it possible to verify that it is completely irregular and not suitable for 2D development through known transformations (without producing unacceptable deformations for the purpose studied here). Similarly, we select the photograph corresponding to the noted oculi that is to be restored (Fig. 5b).
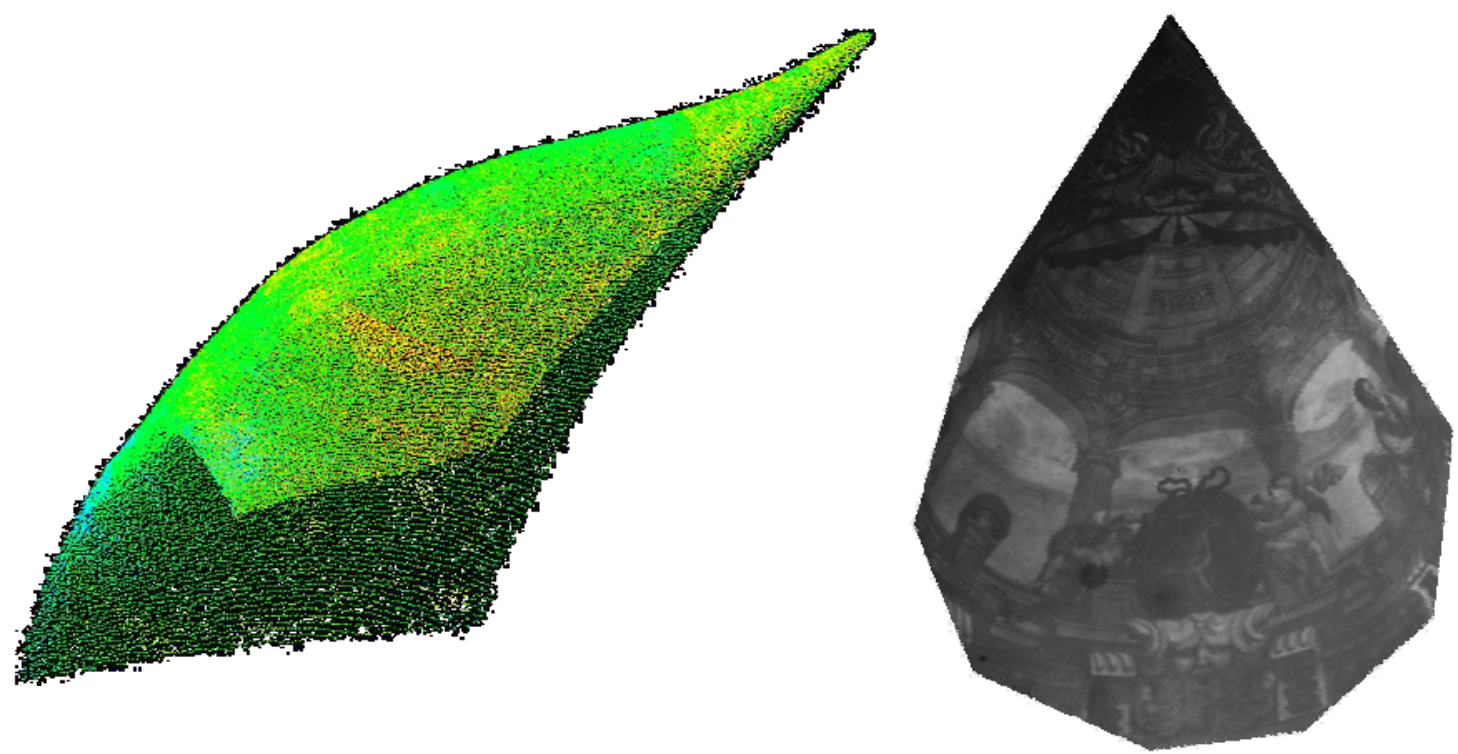

Figure 5: a) Three-dimensional model of the oculus formed by 86,511 points (lateral view). b) Original image of the oculus (not developed).

To perform the development, it is necessary to first establish the triangulation mesh size. To analyse how the indicated algorithm works over the entirety of the element, an adjustment with a mesh size of $50 \mathrm{~cm}$ is made. However, four different adjustments $(50 \mathrm{~cm}, 20 \mathrm{~cm}, 10 \mathrm{~cm}$, and $5 \mathrm{~cm}$ ) are provided, showing the evolution of the weighting parameters and their corresponding adjustment estimators. 


\begin{tabular}{ccccccccc}
\cline { 2 - 8 } & \multicolumn{3}{c}{ Conformal Case } & \multicolumn{2}{c}{ Non-conformal Case } \\
\cline { 2 - 9 } & $\begin{array}{c}\text { Optimal } \\
\text { adjustment } \\
\text { distance }\end{array}$ & $\begin{array}{c}\text { Optimal } \\
\text { adjustment } \\
\text { angular }\end{array}$ & $\begin{array}{c}\text { Optimal adjustment } \\
\text { distance }\end{array}$ & $\begin{array}{c}\text { Optimal adjustment } \\
\text { angular }\end{array}$ \\
\cline { 2 - 9 } & Initial & Adjusted & Initial & Adjusted & Initial & Adjusted & Initial & Adjusted \\
\hline $\begin{array}{c}\text { Angular } \\
\text { weight }\end{array}$ & 20 & 20 & 0.1 & 6.4 & 20 & 20 & 0.1 & 3.53 \\
\hline $\begin{array}{c}\text { Weight in } \\
\text { distance }\end{array}$ & 0.001 & 0.024 & 1 & 1 & 0.001 & 0.024 & 1 & 1 \\
\hline $\begin{array}{c}\sigma \\
\text { Estimator }\end{array}$ & 24.16 & 1.12 & 64.04 & 1 & 24.15 & 1.04 & 35.03 & 0.99 \\
\hline
\end{tabular}

Table 50: Optimal values for the weights for distance (m) and angle (g); $50 \mathrm{~cm}$ mesh size.

\begin{tabular}{cccccccc}
\hline \multicolumn{2}{c}{ Conformal Case } & \multicolumn{3}{c}{ Non-conformal Case } \\
\hline $\begin{array}{c}\text { Optimal } \\
\text { adjustment } \\
\text { distance }\end{array}$ & \multicolumn{2}{c}{$\begin{array}{c}\text { Optimal } \\
\text { adjustment } \\
\text { angular }\end{array}$} & $\begin{array}{c}\text { Optimal adjustment } \\
\text { distance }\end{array}$ & $\begin{array}{c}\text { Optimal adjustment } \\
\text { angular }\end{array}$ \\
\hline Initial & Adjusted & Initial & Adjusted & Initial & Adjusted & Initial & Adjusted \\
\hline 100 & 100 & 0.1 & 1.97 & 20 & 20 & 0.1 & 0.9 \\
\hline 0.001 & 0.002 & 1 & 1 & 0.001 & 0.002 & 1 & 1 \\
\hline 2.1 & 1.09 & 19.72 & 0.98 & 2.08 & 1.04 & 0.99 & 10.76 \\
\hline
\end{tabular}

Table 50: Optimal values for the weights for distance (m) and angle (g); $20 \mathrm{~cm}$ mesh size.

\begin{tabular}{ccccccccc} 
& \multicolumn{3}{c}{ Conformal Case } & \multicolumn{2}{c}{ Non-conformal Case } \\
\cline { 2 - 9 } & \multicolumn{2}{c}{$\begin{array}{c}\text { Optimal } \\
\text { adjustment } \\
\text { distance }\end{array}$} & \multicolumn{2}{c}{$\begin{array}{c}\text { Optimal } \\
\text { adjustment } \\
\text { angular }\end{array}$} & $\begin{array}{c}\text { Optimal adjustment } \\
\text { distance }\end{array}$ & $\begin{array}{c}\text { Optimal adjustment } \\
\text { angular }\end{array}$ \\
\cline { 2 - 9 } & Initial & Adjusted & Initial & Adjusted & Initial & Adjusted & Initial & Adjusted \\
\hline $\begin{array}{c}\text { Angular } \\
\text { weight }\end{array}$ & 200 & 200 & 0.1 & 2.23 & 20 & 20 & 0.1 & 1.5 \\
\hline $\begin{array}{c}\text { Weight in } \\
\text { distance }\end{array}$ & 0.001 & 0.0007 & 1 & 1 & 0.001 & 0.00062 & 1 & 1 \\
\hline $\begin{array}{c}\boldsymbol{\sigma} \\
\text { Estimator }\end{array}$ & 0.67 & 0.96 & 22.37 & 0.96 & 0.62 & 1 & 14.9 & 0.99 \\
\hline
\end{tabular}

Table 50: Optimal values for the weights for distance (m) and angle (g); $10 \mathrm{~cm}$ mesh size.

\begin{tabular}{ccccccccc}
\cline { 2 - 8 } & \multicolumn{3}{c}{ Conformal Case } & \multicolumn{2}{c}{ Non-conformal Case } \\
\cline { 2 - 9 } & $\begin{array}{c}\text { Optimal } \\
\text { adjustment } \\
\text { distance }\end{array}$ & \multicolumn{2}{c}{$\begin{array}{c}\text { Optimal } \\
\text { adjustment } \\
\text { angular }\end{array}$} & $\begin{array}{c}\text { Optimal adjustment } \\
\text { distance }\end{array}$ & $\begin{array}{c}\text { Optimal adjustment } \\
\text { angular }\end{array}$ \\
\cline { 2 - 9 } & Initial & Adjusted & Initial & Adjusted & Initial & Adjusted & Initial & Adjusted \\
\hline $\begin{array}{c}\text { Angular } \\
\text { weight }\end{array}$ & 250 & 250 & 0.1 & 2.97 & 20 & 20 & 0.1 & 2.65 \\
\hline $\begin{array}{c}\text { Weight in } \\
\text { distance }\end{array}$ & 0.001 & 0.0005 & 1 & 1 & 0.001 & 0.00047 & 1 & 1 \\
\hline $\begin{array}{c}\boldsymbol{\sigma} \boldsymbol{E} \\
\text { Estimator }\end{array}$ & 0.5 & 0.91 & 27.91 & 1.02 & 0.47 & 0.95 & 26.48 & 0.99 \\
\hline
\end{tabular}

Table 50: Optimal values for the weights for distance (m) and angle (g); $5 \mathrm{~cm}$ mesh size. 
The adjustments for the $50 \mathrm{~cm}$ mesh, considering all possibilities (conformal and non-conformal, for both conserving angles and distances), are shown in Fig. $X$ (adjustments with the $20 \mathrm{~cm}, 10 \mathrm{~cm}, 5 \mathrm{~cm}$ mesh sizes would be the same, with a much larger number of points).
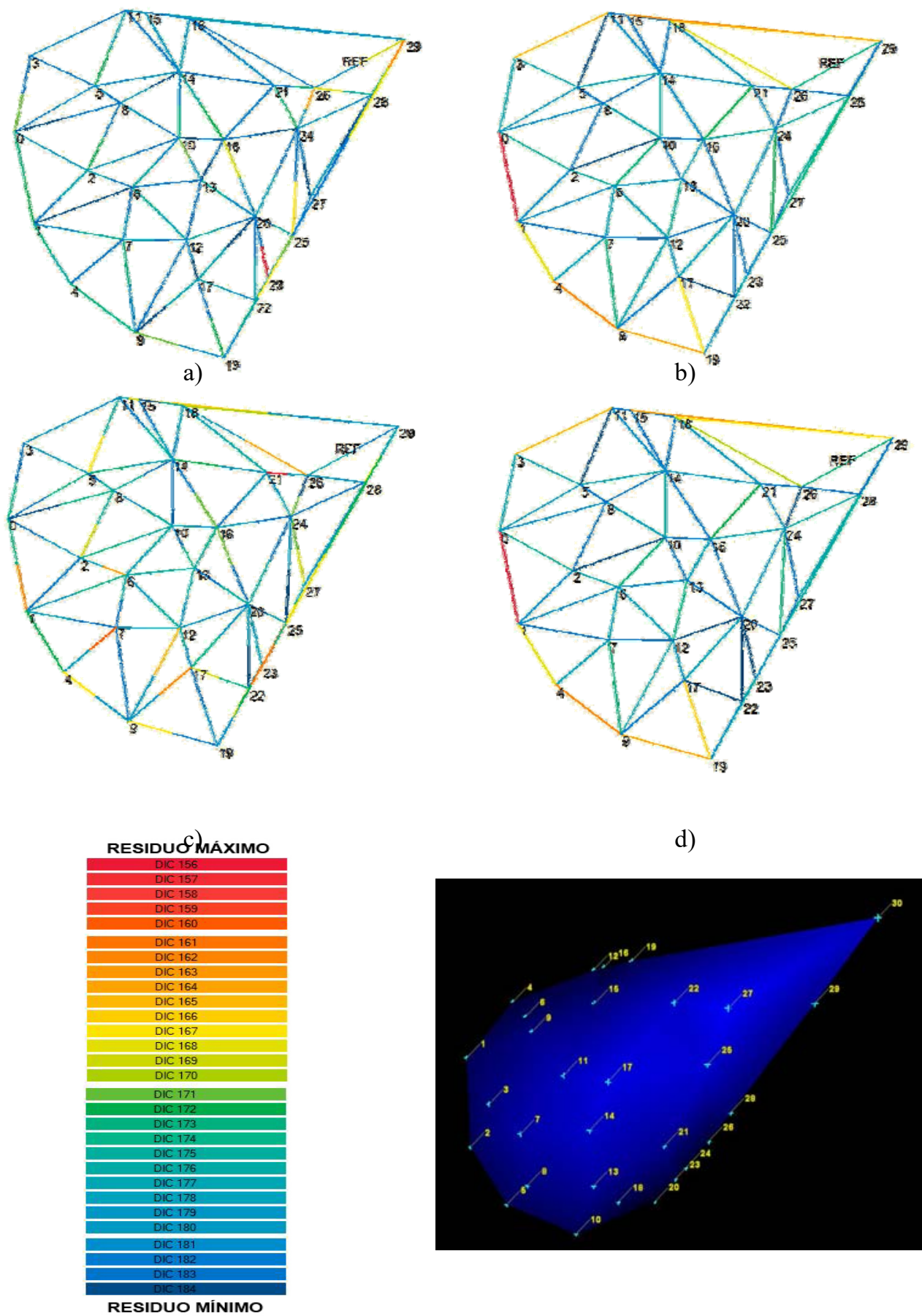

d)

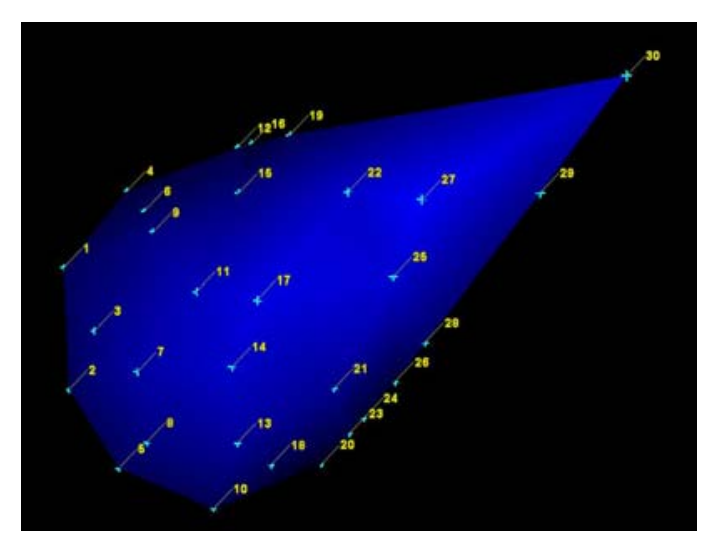

Figure X: a) Development of the mesh with angular remainders. Conformal case. b) Development of the mesh with distance remainders. Conformal case. c) Development of the mesh with angular remainders. Non-conformal case. d) Development of the mesh with distance remainders. Non-conformal case. Legend of remainders. f) Points that define the mesh (106 sides -48 triangles). 
The development of the paintings being restored is next shown through differential rectification of the original oculus photograph based on the four cases previously calculated (Fig. X).
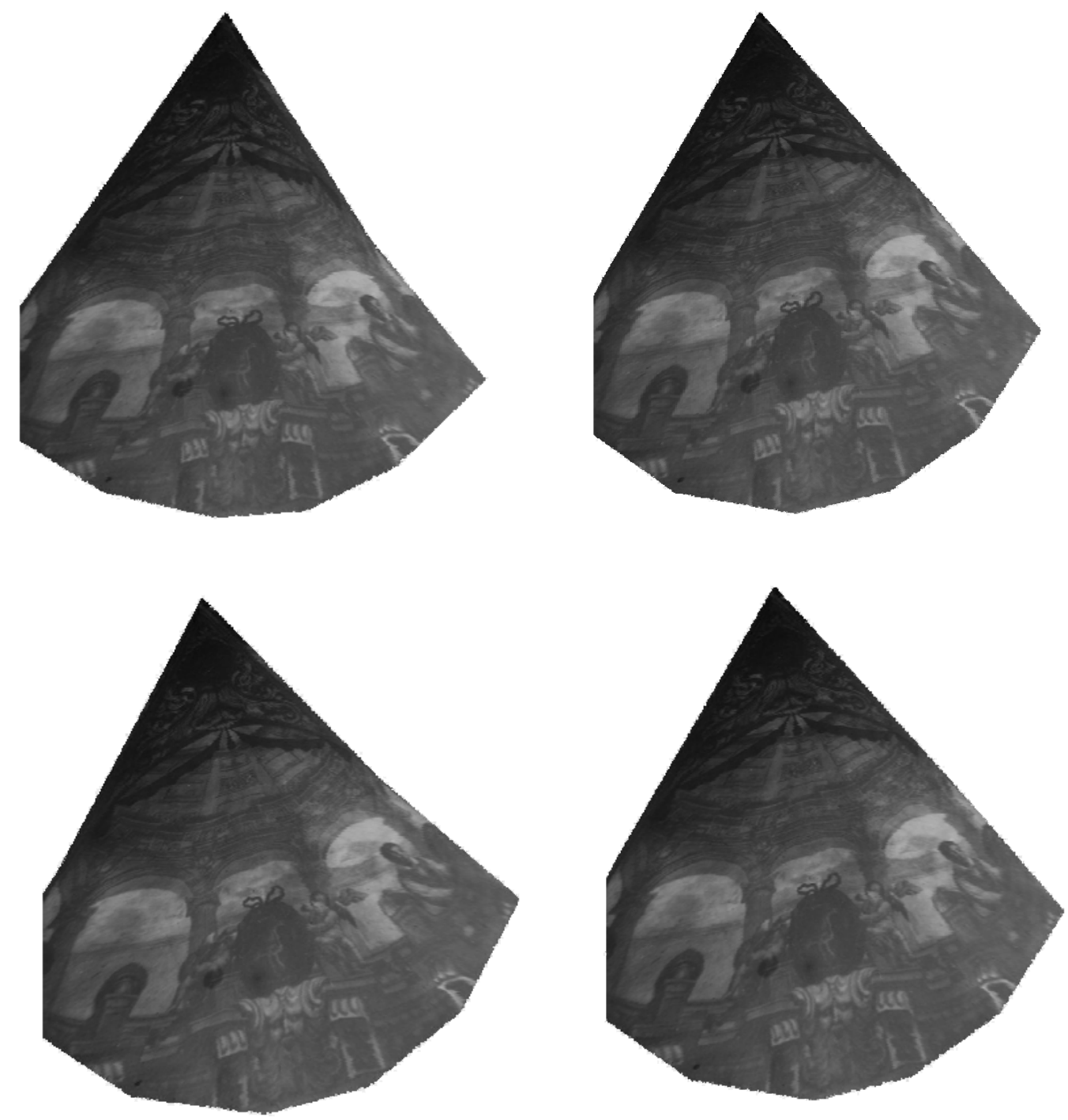

Figure X: a) Conformal 2D development. Angle conservation. b) Conformal 2D development. Distance conservation. a) Nonconformal 2D development. Angle conservation. b) Non-conformal 2D development. Distance conservation.

\section{Conclusions}

The algorithm developed consists of forming a system of calculations through MMCC with angle and distance equations. By assigning weights to one or the other parameter, we make an adjustment and obtain a different development in each case. The possible adjustments are ultimately conformal or nonconformal. Within them, they are adjusted based on distances or angles. In this manner, from each surface, we obtain four different developments. Therefore, the algorithm generates different 2D developments for surfaces that are both developable and non-developable as a function of the parameter that is to be conserved. 
There are different valid solutions based on what needs to be conserved in each case. Although conserving angles is the main objective for navigation, minimizing deformations seems to be the most reasonable solution in engineering, for example. In this manner, the developed algorithm allows the development of surfaces to be modified, which is why the optimal solution can be evaluated and modified at any time. All solutions are exact based on the parameter of conservation of interest in each case. This means that for a specific task, different results can be analysed by comparing the development of a single surface based on different parameters and then deciding which is the most adequate option for each case.

In the case of the cylindrical development, the result does not vary when one or the other solution is used (the projective transformation or the developed algorithm) because it is a developable surface. In the case of the oculus, however, the differences in the developments are notable when conserving different parameters (differences of up to $12 \mathrm{~cm}$ between the case of angle and distance conservation have been observed). The result demonstrates that the algorithm will provide the development that is most advantageous for the restoration team, with the option of varying the conditions being applied based on the desired goals.

Stretching-compressing a surface until it becomes flat is a structural problem (therefore, a study of tensions) in which distances are stretched and/or angles are opened. The weights defined in each case are actually elastic moduli (or resistance to deformation). The energy stored in the entire mechanical system minimizes the sum of the squares of the deformations when applying a specific elastic modulus.

\section{References}

1. Lee I, Lee J, Park H, Bae K. Investigations into the influence of object characteristics on the quality of terrestrial laser scanner data. KSCE Journal of Civil Engineering 2010; 14(6):905-913.

2. Polo ME, Felicísimo AM, Villanueva AG, Martínez-del-Pozo JA. Estimating the Uncertainty of Terrestrial Laser Scanner Measurements. IEEE Transactions on Geoscience and Remote Sensing 2012; 50(11):4804-4808.

3. Gordon SJ, Lichti DD. Modeling terrestrial laser scanner data for precise structural deformation measurement. Journal of Surveying Engineering-ASCE 2007; 133(2):72-80.

4. Park HS, Lee HM, Adeli H, Lee I. A new approach for health monitoring of structures: Terrestrial laser scanning. Computer-Aided Civil and Infrastructure Engineering 2007; 22(1):19-30.

5. Pesci A, Bonali E, Galli C, Boschi E. Laser scanning and digital imaging for the investigation of an ancient building: Palazzo d'Accursio study case (Bologna, Italy). Journal of Cultural Heritage 2012; $13(2): 215-220$.

6. Pesci A, Casula G, Boschi E. Laser scanning the Garisenda and Asinelli towers in Bologna (Italy): 
Detailed deformation patterns of two ancient leaning buildings. Journal of Cultural Heritage 2012; 12(2):117-127

7. Teza G, Pesci A. Geometric characterization of a cylinder-shaped structure from laser scanner data: Development of an analysis tool and its use on a leaning bell tower. Journal of Cultural Heritage $2013 ; 14(5): 411-423$.

8. Jiang R, Jáuregui D, White K. Close-range photogrammetry applications in bridge measurement: Literature review. Measurement 2008; 41:823-834.

9. Faella G, Frunzio G, Guadagnuolo M, Donadio A, Ferri L. The Church of the Nativity in Bethlehem: Non-destructive tests for the structural knowledge. Journal of Cultural Heritage 2012; 13(4):27-41

10. Ercoli L, Megna B, Nocilla A, Zimbardo M. Measure of a Limestone Weathering Degree Using Laser Scanner. International journal of architectural heritage 2013; 7(5): 591-607.

11. Kilambi S, Tipton SM. Development of an algorithm to measure defect geometry using a 3D laser scanner. Measurement Science \& Technology 2012; 23(8):085604.

12. González-Aguilera D, Gómez-Lahoz J, Munoz-Nieto A, Herrero-Pascual J. Monitoring the health of an emblematic monument from terrestrial laser scanner. Nondestructive Testing and Evaluation $2008 ; 23(4): 301-315$.

13. Sumitro S, Matsuda H, Itoh Y, Okamoto T. Dynamic structural analysis using spatial data monitored by 3-d laser scanner. 3rd International Conference on Structural Health Monitoring of Intelligent Infrastructure 2007. Vancouver (Canada).

14. Al-Manasir K, Fraser S. Registration of terrestrial laser scanner data using imagery. Photogrammetric Record 2006; 21(115):255-268.

15. González-Aguilera D, Rodríguez-González P, Gómez-Lahoz J. An automatic procedure for coregistration of terrestrial laser scanners and digital cameras. ISPRS Journal of Photogrammetry and Remote Sensing 2009; 64(3):308-316.

16. Herraez J, Navarro P, Denia JL, Martin MT, Rodriguez J. Modeling the thikness of vaults in the church of Santa María de Magdalena (Valencia, Spain) with laser scanning techniques. Journal of Cultural Heritage 2014 (published on-line 15 Dec 2013)

17. Ma L, Whelan T, Bondarev E, With P and, McDonald J. Planar simplification and texturing of dense point cloud maps. 6th European Conference on Mobile Robots (ECMR) 2013. Barcelona (Spain).

18. Benhabiles H, Aubreton O, Barki H, Tabia H. Fast simplification with sharp feature preseving for 3D 
point clouds. 11th International Symposium on Programming and Systems 2013; 47-52.

19. Ma X, Zheng J, Shui Y, Zhou H, Shen L. A novel method of mesh simplification using Hausdoff distance. 3rd World Congress on Software Engineering 2012;136-139.

20. Li L, Chen SY, Guan Q, Du X, Hu Z.Z. Point cloud simplification based on an affinity propagation clustering algorithm. International Conference on Artificial Intelligence and Computational Intelligence 2009;163-167.

21. Bao-Quan S, Ji L, Qing L. Adaptative simplification of point cloud using k-means clustering. Computer-Aided Design 2011; 43(8):910-922.

22. Hao S, Hsi-Yung F. A global clustering approach to point cloud simplification with a specified data reduction ratio. Computer-Aided Desing 2008; 40(3):281-292

23. Chen S, Guan Q, Li L, Huang W, Qian L. Non-uniform Simplification of Point Clouds. Advanced Materials Research 2011; 311-313:1806-1809.

24. Shi B, Liang J, Liu Q, Xiao Z, Zhang X. A New Data Reduction Algorithm with Preserved Features. Advanced Materials Research 2010; 139-141:1460-1463

25. Yu H, Wang R, Chen J, Liu L, Wan W. Saliency Computation and Simplification of Point Cloud Data. Proceedings of 2nd International Conference on Computer Science and Network Technology $2012 ; 1350-1353$

26. Du X, Yin B, Kong D. Adaptive out-of-core simplification of large point clouds. IEEE International Conference on Multimedia and Expo 2007; 1-5:1439-1442

27. Xiong X, Adan A, Akinci B, Huber D. Automatic creation of semantically rich 3D building models from laser scanner data. Automation in Construction 2013; 31:325-337.

28. Wang Y, Sheng Y, Lu G, Tian P, Zhang K. Feature-constrained surface reconstruction approach for point cloud data acquired with 3d laser scanner. Conference on Optical and Digital Image Processing 2008. Strasbourg (France). 